Gut, 1977, 18, 692-696

\title{
Serum, cerebrospinal fluid, and brain levels of bile acids in patients with fulminant hepatic failure
}

\author{
B. BRON, R. WALDRAM ${ }^{1}$, D. B. A. SILK, AND ROGER WILliaMS \\ From the Liver Unit, King's College Hospital and Medical School, Denmark Hill, London
}

SUMMARY Bile acid levels were measured in the sera, cerebrospinal fluid (CSF), and brain tissue of 10 patients immediately after death from fulminant hepatic failure (FHF). Serum bile acids in FHF were predominantly conjugated, and total bile acid levels were higher in all 10 patients than in normal controls $(85.9 \pm \mathrm{SE} 8.4$ compared with $5.7 \pm 0.4 \mathrm{nmol} / \mathrm{ml}, \mathrm{P}<0.001)$. Small but significant amounts could be detected in CSF (range $1 \cdot 2-5 \cdot 3 \mathrm{nmol}$ total bile acid/ml) and brain biopsies $(1 \cdot 0-18.8 \mathrm{nmol} / \mathrm{g}$ wet weight) of FHF patients, whereas none could be detected in CSF and brain biopsies of patients dying without evidence of liver disease. There was no relationship between serum, CSF, or brain levels and duration of coma, or presence of cerebral oedema found in five FHF patients at necropsy. However, serum bile acid levels were similar in FHF to those found in chronic liver disease without encephalopathy and lower than those found to inhibit brain respiration in vitro. A primary role for these compounds in the pathogenesis of coma in FHF therefore seems unlikely.

Fulminant hepatic failure is a clinical syndrome which develops as a result of massive necrosis of liver cells in a patient who has had no previous evidence of liver disease (Trey and Davidson, 1970). It is characterised by an acute onset of progressive and severe mental changes starting with confusion and rapidly advancing to stupor or coma. Many substances, including ammonia, mercaptans, fatty acids, amino acids, and certain amines have been implicated in the pathogenesis of the coma in these patients (Zieve, 1975), but evidence of a unique role for any single compound is lacking. Recently, conjugated and unconjugated bile salts have been shown to have an inhibitory effect on brain respiration in vitro (Lascelles and Taylor, 1968; Williams and Taylor, 1973). As it is also known that in patients with hepatic coma brain oxygen uptake is reduced (Fazekas et al., 1956), bile salts could be one of the substances involved in the pathogenesis of hepatic coma. The present study was therefore undertaken to investigate the role of these compounds in the pathogenesis of coma in fulminant hepatic failure.

Conjugated and unconjugated bile acid levels were measured in sera, CSF, and brain tissue obtained

${ }^{1}$ Present address: Basingstoke District Hospital, Basingstoke, Hants.

Received for publication 16 February 1977 from 10 patients immediately after death from fulminant hepatic failure.

More than a third of our patients who die in fulminant hepatic failure have evidence of cerebral oedema (Murray-Lyon et al., 1975). Bile salts are known to exert toxic effects on many organs not adapted to their presence (Heaton, 1972). To investigate whether these compounds could be involved in the pathogenesis of the cerebral oedema in FHF, we have also examined the relationship between brain and CSF levels of bile acids and the presence or absence of cerebral oedema at necropsy.

\section{Methods}

\section{SUBJECTS}

Of the 10 patients investigated, hepatic necrosis was caused by paracetamol overdose in four, viral hepatitis (three), and presumed drug idiosyncrasies (three). Duration of grade IV coma (Trey and Davidson, 1970) varied from one to 10 days (Table 1). All patients were treated with full supportive therapy, which included bowel sterilisation, daily enemata, and blood or plasma replacement when necessary. In addition, patients 1,3 , and 5 were treated with daily charcoal haemoperfusion (Gazzard et al., 1974). At necropsy, brain tissue was examined closely for evidence of cerebral oedema, as its 692 
Table 1 Details of 10 patients with hepatic necrosis

\begin{tabular}{|c|c|c|c|c|c|c|c|}
\hline Patient & $\begin{array}{l}\text { Age } \\
(y r)\end{array}$ & Sex & Aetiology & $\begin{array}{l}\text { Duration of } \\
\text { coma (days) }\end{array}$ & $\begin{array}{l}\text { Maximum } \\
\text { prothrombin ratio }\end{array}$ & $\begin{array}{l}\text { Maximum serum } \\
\text { bilirubin (umol/l) }\end{array}$ & $\begin{array}{l}\text { Cerebral oedema } \\
\text { at necropsy }\end{array}$ \\
\hline 1 & 23 & $\mathbf{M}$ & $\begin{array}{l}\text { Drug hepatitis } \\
\text { (diphenylhydantoin) }\end{array}$ & 4 & $78 / 13$ & 200 & + \\
\hline 2 & 20 & $\mathbf{F}$ & Non B hepatitis & 2 & $73 / 13$ & 200 & + \\
\hline 3 & 13 & $\mathbf{M}$ & Non B hepatitis & 5 & $58 / 13$ & 238 & + \\
\hline 4 & 63 & $\mathrm{~F}$ & Halothane hepatitis & 4 & $37 / 13$ & 180 & - \\
\hline 5 & 39 & $\mathbf{F}$ & Paracetamol & 5 & $49 / 12$ & 103 & - \\
\hline 6 & 22 & $\mathbf{F}$ & Non B hepatitis & 3 & $180 / 14$ & 180 & - \\
\hline 7 & 35 & $\mathbf{F}$ & Halothane hepatitis & 1.5 & $85 / 13$ & 380 & + \\
\hline 8 & 28 & $\mathbf{F}$ & Paracetamol & 10 & $44 / 13$ & 260 & + \\
\hline 9 & 24 & $\mathbf{F}$ & Paracetamol & 2 & $92 / 14$ & 163 & + \\
\hline 10 & 39 & $\mathbf{F}$ & Paracetamol & 3 & $63 / 13$ & 173 & + \\
\hline
\end{tabular}

development was often suspected during life. Normal cerebral appearance was found in only three cases $(4,5$, and 6$)$. In cases $1,3,7,8,9$, and 10, marked cerebral oedema with herniation of the cerebral cortex and effacement of the sulci were found and two cases ( 2 and 8 ) had cerebral coning of the temporal lobes through the tentorium cerebelli.

Immediately after death, $10 \mathrm{ml}$ of blood were collected for bile acid measurement and $6 \mathrm{ml}$ CSF drained by lumbar puncture. Brain biopsies were taken by inserting a trocar via the medial aspect of the eyeball and passing it through the superior orbital fissura into the forebrain. The trocar was then withdrawn and a needle advanced at the same time as suction was applied with a syringe.

Control sera were obtained from 14 normal subjects (laboratory personnel aged 19-36 years) for estimation of total and individual bile acid levels. Brain biopsies from four patients and CSF from six patients without evidence of liver disease who had died of other causes were used as controls. The consent of next of kin was always obtained before venepuncture, lumbar puncture, and brain biopsy were performed.

\section{ANALYTIC TECHNIQUE}

Total bile acids of appropriately diluted aliquots of sera and CSF were extracted with XAD 2 (Makino and Sjövall, 1972) and assayed spectroflorimetrically (Murphy et al., 1972). Total bile acids in brain tissue were extracted first by alkaline digestion of at least $300 \mathrm{mg}$ fresh weight of brain (Greim et al., 1973). After neutralisation of the hydrolysate, total bile acids were extracted by Folch extraction. After evaporation under nitrogen and further solid liquid extraction with XAD 2, appropriate aliquots were assayed for total bile acid as described above.

Individual bile acids were separated after the extraction using XAD 2 by thin layer chromatography on silica gel (F-254 Merck) with the solvent dichlorethylene:acetic acid:water (50:50:6.5) (Gregg, 1966). This allowed separation of free trihydroxy and dihydroxy bile acids, their taurine and glycine conjugates, and lithocholic acid. Individual spots were eluted from the plates and assayed individually (Murphy et al., 1972). Deoxycholic acid and chenodeoxycholic acid had the same mobility and were eluted together.

The following recovery experiments for total bile acids were performed. (1) $10 \mathrm{nmol}$ taurocholic acid added to $1 \mathrm{ml}$ control serum $(\mathrm{n}=6)$; recovery was $88.2 \% \pm$ SD $7 \cdot 0 ;$; (2) $100 \mathrm{nmol}$ glycocholic acid added to $1 \mathrm{ml}$ jaundiced serum $(\mathrm{n}=6)$; recovery was $76.2 \% \pm 4.0$; (3) $20 \mathrm{nmol}$ taurocholic acid $(\mathrm{n}=6)$ and $20 \mathrm{nmol}$ deoxycholic acid $(\mathrm{n}=6)$ added to $1 \mathrm{ml}$ CSF; combined mean recovery was $91 \cdot 7 \% \pm 7 \cdot 0$. Recovery of individual bile acids from plasma and CSF was investigated by adding to $1 \mathrm{ml}$ of each a mixture of seven bile acids (taurocholic, taurochenodeoxycholic, glycocholic, glycochenodeoxycholic, cholic, deoxycholic, and lithocholic acid) at a final concentration of each of $2 \mathrm{nmol} / \mathrm{ml}(\mathrm{n}=2), 5$ $\mathrm{nmol} / \mathrm{ml}(\mathrm{n}=2)$, and $10 \mathrm{nmol} / \mathrm{ml}(\mathrm{n}=2)$. Recoveries of the different bile acids were similar at all of the concentrations studied. Recoveries of conjugated and unconjugated bile acids after complete separation by thin layer chromatography were, by addition $88.4 \% \pm$ SD $10.0(n=12)$, and $85.5 \% \pm 6.3(n=$ 12) respectively. Recovery of bile acids from brain tissue was investigated by adding to $100 \mathrm{mg}$ fresh brain 100 and $200 \mathrm{nmol}$ glycocholic acid $(\mathrm{n}=7), 100$ and $200 \mathrm{nmol}$ taurocholic acid $(\mathrm{n}=6)$, and 50, 100 and $200 \mathrm{nmol}$ deoxycholic acid $(\mathrm{n}=6)$. Recovery of each acid was determined after complete separation and combined mean recoveries for glycocholic, taurocholic, and deoxycholic acids were $86.9 \% \pm$ $4 \cdot 0,68 \cdot 5 \% \pm 5 \cdot 3$, and $82 \cdot 6 \% \pm 7 \cdot 9$ respectively.

\section{Results}

TOTAL BILE ACIDS

Serum total bile acid levels were higher in all patients (range $56 \cdot 5-150 \mathrm{nmol} / \mathrm{ml}$ ) as compared with normal subjects (mean $5.7 \pm$ SE $0.4 \mathrm{nmol} / \mathrm{ml}$; 
$P<0.01$ ) (Table 2). Furthermore, small but significant quantities of total bile acids could be detected in CSF (range 1.2 to $5.3 \mathrm{nmol} / \mathrm{ml}$ ) and brain biopsies (range 1.0 to $18.8 \mathrm{nmol} / \mathrm{g}$ fresh weight) in all patients studied, whereas no bile acids could be detected in the CSF and brain biopsies of normal controls.

There were no differences in total bile acid levels in serum, CSF, or brain tissue in the patients with and without post-mortem evidence of cerebral oedema (Fig. 1). Similarly, neither the duration of coma nor the severity of hepatic necrosis appeared to influence the levels of serum, CSF, or brain bile acid.

\section{CONJUGATED AND UNCONJUGATED BILE ACIDS}

In patients with FHF, as in normal subjects, bile acids were present in serum, predominantly as conjugates of taurine and glycine (Fig. 2). In both groups, glycine conjugates predominated, and the ratio of dihydroxy bile acids to trihydroxy bile acids was significantly higher in patients with FHF $(1.76 \pm$ $0.291 \mathrm{SD})$ than in the controls $(1.13 \pm 0.19$, $P<0.05)$. Higher levels of unconjugated bile acids $(7 \cdot 2 \pm 0 \cdot 7)$ were found in the serum of patients than controls $(1.5 \pm 0.1, P<0.02$; values are mean \pm 1 $\mathrm{SE}$, expressed as $\mathrm{nmol} / \mathrm{ml}$ ). Although total bile acid levels in CSF and brain biopsies of patients with FHF were raised compared with controls, it was not possible, because of the low range of levels found in most of them, accurately to measure the ratio of dihydroxy to trihydroxy bile acids nor the ratio of free to total bile acids for the group. However, in the cases where accurate levels could be obtained, glycine and taurine conjugates predominated with only trace amounts or absence of free bile acids.

Table 2 Bile acids in 10 patients with hepatic necrosis

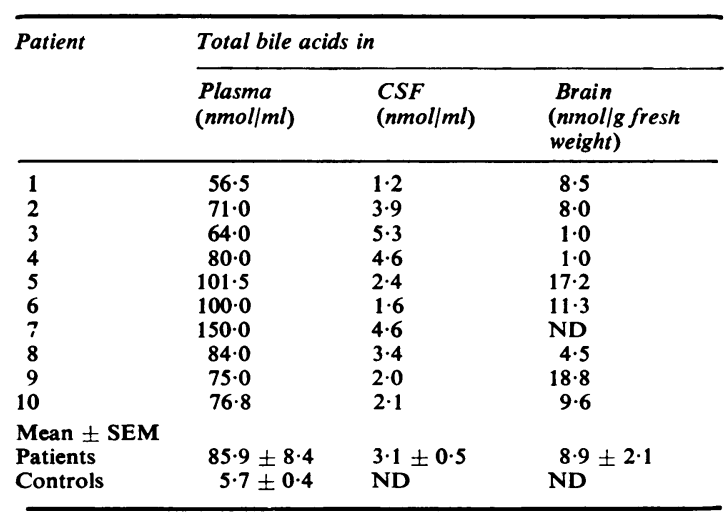

\section{Discussion}

The toxic properties of bile salts are manifold (Heaton, 1972). As already mentioned brain respiration is inhibited in vitro by both conjugated and unconjugated bile acids. Other evidence for the toxic effect of bile salts includes the finding that most hepatocyte (Lee and Whitehouse, 1965; Dean and Whitehouse, 1967; Denk et al., 1971) and enterocyte (Donaldson, 1965; Dietschy, 1967; Clark et al., 1969) metabolic processes are strongly inhibited by free bile acids.

At first sight, bile acids could be directly incriminated in the pathogenesis of hepatic coma because these compounds could be detected in brain tissue and CSF obtained from the patients with FHF, whereas none could be found in the samples obtained from patients dying without evidence of liver disease. However, the concentrations found were much less (range 56-5-150 $\mathrm{nmol} / \mathrm{l}$ ) than the concentrations needed to have a significant inhibitory effect on brain respiration in vitro (2-10 nmol/l) (Lascelles and Taylor, 1968; Williams and Taylor, 1973). Furthermore, in the

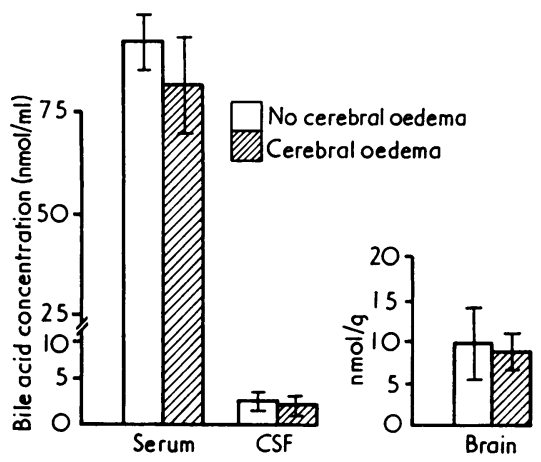

Fig. 1 Total bile acid concentrations in serum, CSF, and brain tissue in the patients dying of fulminant hepatic failure with and without post-mortem evidence of cerebral oedema. Values are mean $\pm S E$.

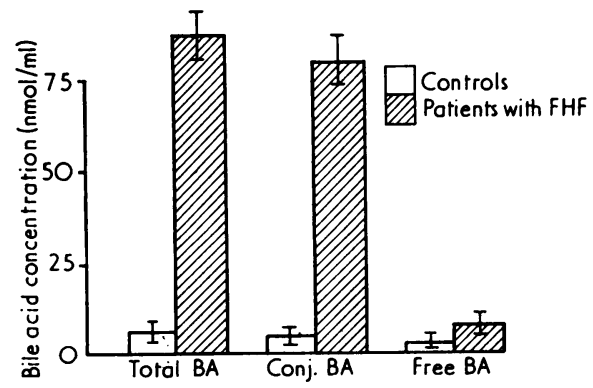

Fig. 2 Concentrations of total, conjugated, and unconjugated bile acids in serum of normal controls and patients with $F H F$. Values are mean $\pm S E$. 
study of brain respiration, unconjugated bile acids were more potent inhibitors than the conjugated forms. As only trace amounts of free bile acids were detected in brain tissue from our patients, a major primary role for bile acids in the pathogenesis of the coma of FHF seems unlikely.

Bile salts are known to cause celiular swelling and vesiculation (Toskes et al., 1975). Such pathogenic effects on brain cells could possibly result in cerebral oedema. However, the brain concentrations of bile acids were low and there was no correlation between brain and CSF concentrations and the presence of cerebral oedema at necropsy, so that it is unlikely that bile acids play an important primary role in the pathogenesis of cerebral oedema. Indeed, there were two patients who had evidence of cerebral oedema at necropsy in whom bile acids were minimal in CSF or brain tissue, and lithocholic acid, the most toxic free bile acid, could not be detected in any of the samples.

Bile acids inhibit the intestinal absorption of several actively transported compounds (Pope et al., 1966; Gracey et al., 1971; Sladen and Harries, 1972; Caspary, 1974) and, in addition, they have been shown to increase the permeability of the colonic mucosa (Dobbins and Binder, 1976). In FHF the blood brain barrier is exposed to high concentrations of bile acids. If bile acids exert similar toxic effects on the blood brain barrier as the gut mucosa, then the normal homeostatic role of the blood brain barrier might be deranged in patients with fulminant hepatic failure. If, as has been suggested, middle molecular weight compounds (MW range 500-5000) are involved in the pathogenesis of coma in FHF (Opolon et al., 1975), then bile acids could increase the permeability of the blood brain barrier, permitting the passage of coma-producing substances from the blood to the brain. In order to establish a pathogenic role for bile acids in hepatic coma at the blood brain barrier level, it will be necessary to investigate the effects of bile acids at the concentration found in the present study on the transport across the blood brain barrier of substances such as amino acids, ammonia, and fatty acids known to be raised in the blood of patients with FHF.

In the present study, the ratio of dihydroxy to trihydroxy acids (1.7) was raised in FHF. The same observation has been reported in patients with hepatic cirrhosis who had severe hepatic cell damage (Carey, 1969). In normal subjects the ratio is 1 or less (Carey, 1969). The explanation for the raised ratio is unclear. It is known that the normal half life of the primary trihydroxy acid is less than that of the primary dihydroxy acid (Danielsson et al., 1963; Vlahcevic et al., 1971). If the same is the case in FHF, and synthesis of both acids severely depressed, there would be a tendency for the ratio to become raised.
Detailed studies of bile salt kinetics in FHF will have to be performed, however, before firm conclusions can be drawn.

Finally, although circulating levels of bile acids were raised in FHF, the absolute values (range 56.5$150 \mathrm{nmol} / \mathrm{l}$ ) were of the same magnitude as reported in less severe forms of liver disease (Makino et al., 1969; Neale et al., 1971; Murphy et al., 1972). In FHF severe intrahepatic cholestasis occurs (Gazzard et al., 1974), so that there is reflux of conjugated bile acids into the systemic circulation. The absolute concentrations of circulating bile acids will therefore depend upon the hepatic synthesis rates. As up to $80 \%$ of hepatocytes are destroyed in fulminant hepatic failure (Gazzard et al., 1974), circulating bile acid concentrations higher than those found in less severe forms of liver disease would not be expected.

\section{References}

Carey, J. B. (1969). Bile salts in hepatobiliary disease. In Diseases of the Liver, 3rd ed., pp. 103-146. Edited by L. Schiff. Lippincott: Philadelphia.

Caspary, W. F. (1974). Inhibition of active hexose and amino acid transport by conjugated bile salts in rat ileum. European Journal of Clinical Investigation, 4, 17-24.

Clark, M. L., Lanz, H. C., and Senior, J. R. (1969). Bile salt regulation of fatty acid absorption and esterification in rat everted jejunal sacs in vitro and into thoracic duct lymph in vivo. Journal of Clinical Investigation, 48, 1587-1599.

Danielsson, H., Eneroth,P., Hellström, K., Lindstedt, S., and Sjövall, J. (1963). On the turnover and excretory products of cholic and chenodeoxycholic acid in man. Journal of Biological Chemistry, 238, 2299-2304.

Dean, P. D. G., and Whitehouse, M. W. (1967). Inhibition of hepatic sterol oxidation by cholanic (bile) acids and their conjugates. Biochimica et Biophysica Acta, 137, 328-334.

Denk, H., Greim, H., and Hutterer, F. (1971). Detergent action of bile acids on hepatocellular microsomes, and its role in cholestasis. Gastroenterology, 60, 187. (Abstract.)

Dietschy, J. M. (1967). Effect of bile salts on intermediate metabolism of the intestinal mucosa. Federation Proceedings, 26, 1589-1598.

Dobbins, J. W., and Binder, H. J. (1976). Effect of bile salts and fatty acids on the colonic absorption of oxalate. Gastroenterology, 70, 1096-1100.

Donaldson, R. M. (1965). Studies on the pathogenesis of steatorrhea in the blind loop syndrome. Journal of Clinical Investigation, 44, 1815-1825.

Fazekas, J. F., Ticktin, H. E., Ehrmantraut, W. R., and Alman, R. W. (1956). Cerebral metabolism in hepatic insufficiency. American Journal of Medicine, 21, 843-849.

Gazzard, B. G., Weston, M. J., Murray-Lyon, I. M., Flax, H., Record, C. O., Portmann, B., Langley, P. G., Dunlop, E. H., Mellon, P. J., Ward, M. B., and Williams, R. (1974). Charcoal haemoperfusion in the treatment of fulminant hepatic failure. Lancet, 1, 1301-1307.

Gracey, M., Burke, V., and Oshim, A. (1971). Reversible inhibition of intestinal active sugar transport of deconjugated bile salts in vitro. Biochimica et Biophysica Acta, 225, 308-314.

Gregg, J. A. (1966). New solvent systems for thin layer chromatography of bile acids. Journal of Lipid Research, 7, 579-581. 
Greim, H., Czygan, P., Schaffner, F., and Popper, H. (1973). Determination of bile acids in needle biopsies of human liver. Biochemical Medicine, 8, 280-286.

Heaton, K. W. (1972). Bile salt deficiency and bile salt toxicity. Bile Salts in Health and Disease, pp. 116-124. Churchill Livingstone: Edinburgh.

Lascelles, P. T., and Taylor, W. H. (1968). The effect upon tissue respiration in vitro of metabolites which may accumulate in hepatic coma. Clinical Science, 35, 63-71.

Lee, M. J., and Whitehouse, M. W. (1965). Inhibition of electron transport and coupled phosphorylation in liver mitochondria by cholanic (bile) acids and their conjugates. Biochemica et Biophysica Acta, 100, 317-328.

Makino, I., and Sjövall, J. (1972). A versatile method for analysis of bile acids in plasma. Analytical Letters, 5, 341. 349.

Makino, I., Nakagawa, S., and Mashimo, K. (1969). Conjugated and unconjugated serum bile acid levels in patients with hepatobiliary diseases. Gastroenterology, 56, 10331039.

Murphy, G. M., Ross, A., and Billing, B. H. (1972). Serum bile acids in primary biliary cirrhosis. Gut, 13, 201-206.

Murray-Lyon, I. M., Portmann, B., Gazzard, B. G., and Williams, R. (1975). Analysis of the causes of death in the treatment failures. In Artificial Liver Support, pp. 242-249. Edited by R. Williams and I. M. Murray-Lyon. Pitman Medical: Tunbridge Wells.

Neale, G., Lewis, B., Weaver, V., and Panveliwalla, D. (1971). Serum bile acids in liver disease. Gut, 12, 145-152.

Opolon, P., Lavallard, M. C., Crubille, C., Gateau, P., Nusinovici, V., Granger, A., Darnis, F., and Caroli, J.
(1975). Encéphalopathie au cours de l'atrophie hépatique aiguẹ. Effet de l'épuration des moyennes molécules. Résultats préliminaires. Nouvelle Presse Médicale, 4, 2987- 2991.

Pope, J. L., Parkinson, T. M., and Olson, J. A. (1966). Action of bile salts on the metabolism and transport of watersoluble nutrients by perfused rat jejunum in vitro. Biochimica et Biophysica Acta, 130, 218-232.

Sladen, G. E., and Harries, J. T. (1972). Studies on the effects of unconjugated dihydroxy bile salts on rat small intestina function in vivo. Biochimica et Biophysica Acta, 288, 443456.

Toskes, P. P., Giannella, R. A., Jervis, H. R., Rout, W. R., and Takeuchi, A. (1975). Small intestinal mucosal injury in the experimental blind loop syndrome. Gastroenterology, 68, 1193-1203.

Trey, C., and Davidson, C. S. (1970). The management of fulminant hepatic failure. In Progress in Liver Disease, vol. 3, p. 282. Edited by H. Popper and F. Schaffner. Grune and Stratton: New York.

Vlahcevic, Z. R., Miller, J. R., Farrar, J. T., and Swell, L. (1971). Kinetics and pool size of primary bile acids in man. Gastroenterology, 61, 85-90.

Williams, C. P., and Taylor, W. H. (1973). Effect on brain respiration in vitro of conjugated and unconjugated bile salts and their possible role in hepatic coma. Biochemical Society Transactions, 1, 146-149.

Zieve, L., (1975). Metabolic abnormalities in hepatic coma and potential toxins to be removed. In Artificial Liver Support, pp. 11-26. Edited by R. Williams and I. M. Murray-Lyon. Pitman Medical: Tunbridge Wells. 